\title{
Vagueness in Law and Language: Some Philosophical Issues
}

\author{
Jeremy Waldron $\dagger$
}

\section{INTRODUCTION}

This Article is devoted to a philosophical account of the various problems with meaning that lawyers associate with the "void-for-vagueness" doctrine. I shall not attempt any detailed consideration of the doctrine itself. Apart from some comments in the concluding section, my contribution is intended to set the conceptual stage for, rather than preempt, the substantive discussion of problems of vagueness in the law. I am employed here, in John Locke's words,

as an underlabourer in clearing ground a little, and removing some of the rubbish that lies in the way of knowledge; which certainly had been very much more advanced in the world, if the endeavours of ingenious and industrious men had not been so much encumbered with the learned but frivolous use of uncouth, affected, or unintelligible terms. ${ }^{1}$

I

\section{A Preliminary Point About Meaning}

Scholars in the Critical Legal Studies movement tell us that jurisprudence used to be dominated by "formalism," which is the doctrine that words determine their own applications to the objects to which they apply. It is difficult to state this formalist doctrine coherently (which is probably one of the reasons why, despite CLS claims, no legal philosopher ever held it), but Margaret Jane Radin's statement is typical of many:

In the traditional conception of the nature of rules, a rule is self-applying to the set of particulars said to fall under it; its application is thought to be analytic. It is often said that rules are logically prior to the particular cases that fall under them. Another way of

Copyright @ 1994 California Law Review, Inc.

$\dagger$ Associate Dean and Professor of Law and Philosophy, Jurisprudence and Social Policy Program, Boalt Hall School of Law and Department of Philosophy, University of California, Berkeley. B.A. 1974, LL.B. (Hons.) 1978, University of Otago; D.Phil. 1986, University of Oxford.

1. 1 John Locke, An Essay Concerning Human Understanding at xxxv (J. Yolton ed., 1978) (quote from Locke's introductory "Epistle to the Reader"). 
putting this is to think that somehow the applications to particulars are already present in the rule itself. ${ }^{2}$

This traditional view, Radin goes on, is mistaken: as a matter of fact, there is no way of telling deductively or analytically when a rule is being followed. ${ }^{3}$ Words do not determine meanings, people do. No amount of staring at the words of a rule, then staring at the world, then staring at the words again, will tell us when we have a proper application. Radin's observation is true but trivial, and my preliminary claim in this Part is that it has nothing to do with the issue of vagueness.

Think of the least vague expression you can imagine being used in legislation-say, "less than twenty-one years old" in an ordinance prohibiting serving alcohol to minors. The phrase itself does not light up in the presence of an infant and then go out in the presence of a forty year old, like an ultra-sensitive neon sign at the doorway to a bar. The rule about not serving people under twenty-one is not like a geiger counter that emits a loud clicking whenever a teenager enters the premises. Even when expressions are precise, it is people who must apply the words.

True, people do so by using analytic meaning rules. " $X$ is $n$ years old" means the same as "A period of time which is no less than $n$ years, and less than $n+1$ years, has elapsed since the beginning of the day on which $X$ was born." If someone wants to know the meaning of "year," we define it analytically in this context as "a period of time equal to one year of the Gregorian calendar but beginning [possibly] at a different time." ${ }^{4}$ We can go on, if necessary, to define the Gregorian system of 365 and $1 / 4$ days, the meaning of "day" in terms of hours, minutes, seconds, and so on. But these are analytic connections between words and words, not between words and things. Eventually, if we are dealing with a complete neophyte who asks "But what is a second?" we may have to define some period of time ostensively: taking the neophyte to the Greenwich observatory and saying "Listen! - the length in time of this tone is a second." That observation is a relation between a word and a thing, but it is not analytic or deductive.

2. Margaret J. Radin, Reconsidering the Rule of Law, 69 B.U. L. Rev. 781, 795 (1989).

3. See id. at 798 (interpreting Ludwig Wittgenstein in Philosophical Investigations).

4. Webster's Ninth New Collegiate Dictionary 1366 (1991) [hereinafter Webster's] (definition 2(b) of "year").

In addition, there is a whole array of considerations about the analytic/synthetic distinction that 1 cannot go into here. Clearly, there are circumstances imaginable in which we would modify the connection between "year," the Gregorian system, and our statistical understanding of the time it takes the earth to circle the sun. Does this show that the meaning I have given for year is a synthetic (c.g., astronomical) claim, rather than an analytic (c.g., verbal) claim? See W.V.O. QuiNe, From A LoGiCAL PoINT OF VIEW at v (2d ed. 1961) (criticizing the "analytic/synthctic" distinction); see also SAUL A. KRIPKe, Naming AND NeCEssity 3-15, 61-164 (1980) (discussing "rigid designators").

5. Or we may have to start all over again in the higher reaches of the language and say a second is the "unit of time equal to the duration of 9,192,631,770 periods of the radiation corresponding to the transition between the two hyperfine levels of the ground state of the cesium-133 atom." WEBSTER's, supra note 4, at 1060 (definition 1 (b) of " 2 second"). 
Moreover, a whole apparatus of social practice, about the word "this" and about what it means for time to elapse, is presupposed in this ostension. If the neophyte has not grasped all that, no amount of hand-waving in the presence of tones will help.

Since words do not apply themselves, since it is we who apply them to cases, of course we may need further rules for their application, and of course we will eventually run out of analytic meaning-rules before a precise application is determined. There cannot be a rule to tell us how to apply every rule: sooner or later one simply makes a judgment. ${ }^{6}$ Ludwig Wittgenstein, in his later work, is responsible for the insight that judgment cannot itself amount to "following a rule" in one's own mind; in the end, it must come down simply to participating with others in a form of life. ${ }^{7}$

My point is this: these difficulties and considerations concerning how words "have" meanings are independent of and prior to any issue about vagueness. For suppose words and rules were as the formalists thought they were: suppose they lit up like a neon sign or clicked like a Geiger counter in the presence of the objects to which they applied. Even if that were how meanings worked, there would still be the problem of how to interpret a slight, hesitant clicking or a dull flickering of the word in the presence of borderline cases. In fact, words are not Geiger counters and no one ever thought they were. We have to give an alternative account-say, a sociological account, along Wittgenstenian lines-of how words have the meanings they do. It is important, moreover, to see that unless the problem of meaning is solved, the issue of vagueness cannot even arise. We cannot know that a word is vague, unless we know something about its use. So although vagueness is a problem for the theory of meaning, the very postulation of the problem assumes that the basic question-of what it is for a word to have meaning-has in some way or another been settled.

6. See, for example, Kant's construction of the role of judgment:

For a concept of the understanding, which contains the general rule, must be supplemented by an act of judgment whereby the practitioner distinguishes instances where the rule applies from those where it does not. And since rules cannot in tum be provided on every occasion to direct the judgment in subsuming each instance under the previous rule (for this would involve an infinite regress), theoreticians will be found who can never in all their lives become practical, since they lack judgement.

Immanuel Kant, On the Common Saying: "This May be True in Theory, But It Does Not Apply in Practice," in Kant: Polttical Wrmings 61, 61 (Hans Reiss ed. \& H.B. Nisbet trans., 2d ed. 1991).

7. Ludwig Wittgenstein, Philosophical Investigations paras. 66-276, at 31e-96e (G.E.M. Anscombe trans., 1974). For a convincing argument that there is no warrant in Wittgenstein's theory for a greater indeterminacy in the use of language than traditional legal scholars have supposed, see Brian Bix, The Application (and Mis-Application) of Wittgenstein's Rule-Following Considerations to Legal Theory, in Wittgenstein and Legal Theory 209 (Dennis M. Patterson ed., 1992). 


\section{II}

\section{SOME Definitions}

Let us turn now to the specific problems about meaning with which the "void-for-vagueness" doctrine is concerned. In the philosophical literature, ambiguity is different from contestability, and both are different from vagueness. If we want a general term to cover all three, we may use "indeterminacy."

The term "blue" is ambiguous because it is used sometimes to indicate a color and sometimes to indicate a mood. Accordingly, we may be unclear what someone means when she says, "His smile was happy and his eyes were blue." Further, even if we are sure that "blue" is being used to describe a color, we know that it suffers from vagueness: there are shades of turquoise that we might classify as blue or green, and there are shades of lavender that we might classify as blue or purple.

The phrase "due process" has long been ambiguous in America: constitutional lawyers find they have to affix additional terms as in "substantive due process" and "procedural due process" to sort the ambiguity out. In addition, each of those terms is contested. ${ }^{8}$ Some say, for example, that "procedural due process" requires municipal agencies to hold public hearings in response to planning applications; others deny this. Such disagreement is a dispute about the social norms and moral standards that are or ought to be embodied in the phrase. The existence of those disputes makes the meaning of the phrase contestable. Contestability, then, is different from the uncertainty we might have about "his eyes were blue" or about the classification of a certain shade of turquoise: the latter uncertainties are not in and of themselves uncertainties about norms (other than norms for the use of language).

Let me propose some preliminary definitions, which will serve as points of reference, and some examples of the application of the definitions:

(i) AMBIGUITY: An expression $X$ is ambiguous if there are two predicates $P$ and $Q$ which look exactly like $X$, but which apply to different, though possibly overlapping, sets of objects, with the meaning of each predicate amounting to a different way of identifying objects as within or outside its extension.

Example: "Blue" is ambiguous for there are two predicates"blue"(-colored) and "blue" (melancholy) - which look the same but apply to different objects. As a matter of meaning, the application of the first of these predicates is determined by looking at an object's color; the application of the second is determined by looking at the object's mood.

8. And so, perhaps, is the existence of the ambiguity: some say that "substantive due process" is an oxymoron, and "procedural due process" a pleonasm; they deplore the fact that this distinction has found a place in constitutional jurisprudence. 
(ii) VAGUENESS: A predicate $P$ is vague if there are objects or instances $x_{1}, x_{2}$, etc. within the domain of the normal application of terms of this kind such that users are characteristically undecided about the truth or falsity of " $x_{1}$ is $P$, " " $x_{2}$ is $P$," and they understand that indecision to be a fact about the meaning of $P$ rather than about the extent of their knowledge of $x_{1}, x_{2}$, etc.

Example: "Blue"-colored is vague because, although the predicate is supposed to apply to and discriminate among color patches, most of us would hesitate about saying of certain shades of turquoise and lavender either that they were blue or that they were not blue. We would regard them as borderline cases, perhaps undecidable except by arbitrary stipulation. Our hesitation would not be because we had only had a glimpse of the patches in question and needed a closer look. We would say rather that even under optimal conditions of perception the meaning of the word "blue" did not determine an answer.

(iii) CONTESTABILITY: A predicate $P$ is contestable if (1) it is not implausible to regard both "something is $P$ if it is $A$ " and "something is $P$ if it is $B$ " as alternative exphications of the meaning of $P$; and (2) there is also an element $e^{*}$ of evaluative or other normative force in the meaning of $P$; and (3) there is, as a consequence of (1) and (2), a history of using $P$ to embody rival standards or principles

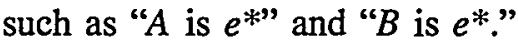

Example: The term "democracy" is contestable, because (1) while it is plausible to explicate its meaning in terms of representation, it is also not implausible to explicate its meaning in terms of direct participation in government; (2) the term has a favorable evaluative meaning (" $e *$ " $=$ "ought to be promoted," etc.); and (3) there is, as a consequence of (1) and (2), a history of using the term "democracy" to embody rival political principles such as "Every political system should have a representative structure" and "We ought to encourage direct popular participation in government."

The term "vagueness" in the "void-for-vagueness" doctrine is almost certainly indeterminate in all the ways mentioned above. ${ }^{9}$ Its meaning certainly comprises both vagueness in the strict sense and ambiguity, and in a

9. The terms "vagueness," "contestability," and "ambiguity" are themselves vague, contestable, and ambiguous. For example, it is not clear when the metaphorical use of a term becomes ambiguity; certainly a metaphor is different from a homonym. The vagueness of a term like "torture" (Is sensory deprivation torture?) may well become contestability, or the vehicle for contestability, to the extent that "torture" is used to articulate normative standards such as those laid down in Article 3 of the European Convention on Human Rights. The European Court of Human Rights held, for example, in Ireland v. United Kingdom, 25 Eur. Ct. H.R. (ser. A) at 65, 67 (1978), that certain interrogation techniques used by the security forces in Northern Ireland, though they caused intense physical and mental distress to the 
legal context, either of those forms of indeterminacy is likely to become contestability if there is a history of political argumentation about the meaning of the term. ${ }^{10}$ Maybe "vagueness" is supposed to refer to any form of indeterminacy that encourages unwarranted discretion or leaves the citizen without reasonable notice of what is required of her. But even if we sort out its ambiguity using phrases like "arbitrary discretion" and "reasonably clear guidelines," the meaning of those phrases is likely in turn to be both vague and contested.

The definitions I have offered should be treated with some care in a legal context. In defining a strict philosophical sense of "vagueness" and distinguishing it from other forms of indeterminacy, it is not my intention to pin down the true neaning of the "void-for-vagueness" doctrine. The fact that philosophers have given "vagueness" a reasonably precise definition does not at all imply that constitutional lawyers should attach the sanie meaning to the term. Precision, as Aristotle reminded us, is always relative to a subject and the purpose for which it is undertaken. ${ }^{11}$ I am drawing these distinctions-following general philosophical usage-only so that we can see and understand the diverse sources of indeterminacy that flow from the use of natural language in both descriptive and normative contexts.

I now want to develop some detailed comments on the various types of indeterminacy that I have defined.

persons subjected thereto and led to acute psychiatric disturbances during interrogation, "did not occasion suffering of the particular intensity and cruelty implied by the word torture as so understood."

Some writers deny that there is a phenomenon of conceptual contestability distinct from ambiguity and persuasive definition; others have responded that the idea of contestability is itself contestable. See, e.g., William E. Connolly, The Terms of Polmtical Discourse (2d ed. 1983); John Gray, On Liberty, Liberalism and Essential Contestability, 8 BRIT. J. Pol. Scr. 385 (1978); Alasdair Maclntyre, The Essential Contestability of Some Social Concepts, 84 Erulcs 1 (1973).

Thomas Hobbes is famous for the suggestion that all verbal indeterminacy is in the end contestability: people only care about definitions when interests are at stake.

Which is the cause, that the doctrine of Right and Wrong, is perpetually disputed, both by the Pen and the Sword: Whereas the doctrine of Lines, and Figures, is not so; because men carc not, in that subject what be truth, as a thing that crosses no mans ambition, profit, or lust. For I doubt not, but if it had been a thing contrary to any mans right of dominion, or to the interest of men that have dominion, That the three Angles of a Triangle should be equall to two angles of a Square; that doctrine should have been, if not disputed, yet by the buming of all books of Geometry, suppressed, as farre as he whom it concerned was able.

Thomas Hobbes, Leviathan ch. XI, at 73-74 (Richard Tuck ed., 1991) (1651).

10. Ambiguity, it can be argued, is a special case of vagueness, see IsRAEl ScheFfler, BEYoND the LetTer: A Philosophical Inquiry into Ambiouity, Vaqueness and Metaphor in Languagb 37-40 (1979), and perhaps the first condition in the definition of contestability depends on vagueness also. Contestability will behave like ambiguity in certain contexts, and ambiguity can become contestability when something moral or political seems to be at stake in a discussion about the proper meaning of a term.

11. Aristotze, Nicomachean Ethics 1.3 1094b23-28 (Martin Ostwald ed. \& trans., 1962) ("For a well-schooled man is one who searches for that degree of precision in each kind of study which the nature of the subject at hand admits: it is obviously just as foolish to accept arguments of probability from a mathematician as to demand strict demonstrations from an orator."). 
III

\section{AMBIGUITY}

Most of my remarks will be devoted to vagueness and contestability. This is not because ambiguity is uniniportant but because it is the most easily understood of the three, and the niost amenable to simple resolution. When our friend says "His smile was happy and his eyes were blue," we can simply ask her what she means: "Blue-colored or blue melancholy?"

In most cases of ambiguity, the look-alike predicates are so divergent in meaning that context will nrake it clear which one was intended. If the context does not make it clear, we may be faced with such a spectacular failure of communication as to nuake the interpretive enterprise all but impossible. Suppose the legislature has presented us with a provision setting up an agency to supervise "banks," and a court really is unsure, both from context and from legislative history, whether it is dealing with financial niatters or riparian matters. Suppose also that there is now no way of asking the legislators what they meant-banking institutions or riverbanks? Since it is clear they nieant one or the other-for there is, fortunately, no third honionym in play - sonieone may suggest that the two meanings of "bank" define the limits of our interpretive freedom: by choosing one meaning or the other, we have a greater probability of according with legislative intentions than if we simply write a new law ourselves.

But there is soniething ludicrous about this choice. If the legislators really did mean riverbanks, then an "interpretation" that focuses on financial institutions is about as far as could be imagined front their intentions and could not possibly be regarded as an instance of institutional deference. We should not think that by pursuing one or the other meaning of this string of letters (b-a-n-k), we are deferring to the legislature in a way that we would not be if, for example, we developed a general policy of our own about land use in place of the problematic provision. Another way of putting this is to insist that the problem of interpretation cannot get underway until we have at least a ball-park sense of the sort of message intended to be conveyed by the sounds and inscriptions that the legislature used. ${ }^{12}$

Not all ambiguity is honronymy. Occasionally the look-alike predicates will be so related to one another, semantically or etymologically, that some sort of interpretive exercise will be appropriate. Two cases spring to mind.

Sometimes ambiguity arises because of different levels of generality at which a term is used. ${ }^{13} \mathrm{~A}$ term in my lease may read "Animals are prohibited on the premises except cats and dogs." Now my pet, Baby, is a cat; but she is a full-grown leopard rather than a small nrouse-chasing aninial of the

12. See the discussion of "the preinterpretive stage" in RONALD DWORKIN, LAw's EMPIRE 65-66 (1986).

13. See SCHEFrER, supra note 10 , at 14-15. 
species felis catus. We may wonder whether my landlord really meant to include all animals of the Felidae family within her general permission. There may be intermediate cases: suppose I manage to tame a small ocelot. If it is size and behavior rather than strictly speaking species that my landlord wanted to exempt from the prohibition, the ocelot may be permissible. But then what about a slightly larger member of the Felidae family? Clearly what is going on here is a slip from ambiguity into vagueness.

Another sort of non-homonymous ambiguity arises from the fact that some terms have technical meanings as well as natural meanings, and some terms with technical meanings have several inconsistent or equivocal technical meanings depending on which technician you listen to. A notorious example is "economic efficiency." Because economists have developed subtly different theories to address overlapping problems, we find that "efficiency" is used to characterize the pursuit of Pareto-optimality, the maximization of wealth, the use of the Kaldor-Hicks criterion, the maximization of utility in the traditional Benthamite sense, and the cost-effective pursuit of public policy. ${ }^{14}$ The matter is not helped by the fact that earlier transfers of jargon from economics to ordinary language have given us a meaning of efficiency that refers ambiguously to the profitable operation of a business, to a certain sort of no-nonsense briskness, and to the clear-headed pursuit of any goals by anyone. ${ }^{15}$ What we see in this case is a transformation of ambiguity into contestability: a technical term, defined initially in an illcoordinated way, takes on an evaluative force which other definers seek to capture and exploit for the purposes of social and economic theories. Much of what I later say about contestability will apply to this species of ambiguity.

IV

The Philosophers' Concept of Vagueness

In defining vagueness, I used a color-word as an example. Colors seem particularly liable to vagueness. The difficulty seems to be that, in the case of colors, we use classificatory terms to divide up a sensory continuum. In general, problems of vagueness will arise whenever we confront a continuum with terminology that has, or aspires to have, a bivalent ${ }^{16}$ logic. On the one hand, there is this subtle gradation of hues; on the other hand, surely something either is blue or is not blue. On the one hand, humans

14. For an excellent discussion, see Jules L. Coleman, Markets, Morals and the Law 95-132 (1988).

15. For litigation in England in which the meaning of "efficiency" was crucially at issue, sce Bromley London Borough Council v. Greater London Council, [1982] 1 All E.R. 129 (C.A. \& H.L.). There is a discussion of this case and its implications for interpretive disputes in JeREMY WALDRON, THE LAw 117-50 (1990).

16. "Bivalent" meaning "two-valued." Most if not all of our logic depends on our being able to assign just one of two truth values (true or false) to eacb proposition. So a statement like "The sky is blue today" is either (1) true or (2) false; there is, in a bivalent framework, no third alternative. 
range imperceptibly in age from zero to more than a hundred years old; on the other hand, surely it is either true or false, at a given time, that Sam is a youth and not an adult. And so on for all sorts of terms: "short" and "tall" classifying persons on the continuum of height; "village," "town," and "city" classifying communities on the continuum of population; "rich" and "poor" classifying individuals on continua of wealth and income; "careful," "negligent," and "reckless" classifying behavior on a continuum of attentiveness. ${ }^{17}$

The philosophical significance of this sort of vagueness is symbolized by the Sorites Paradox:

A series of things could be arranged in such a way that the first consists of a large heap of grains of some kind and each subsequent member consists of grains of the same kind but contains, in each case, one less grain than the one before.... The last member, which consists of a single grain, is obviously not a heap. But if any member of the series is a heap, then it would surely remain so if just one grain were subtracted. The application conditions for the predicate ["heap"] are not sharp enough to distinguish heaps from non-heaps on the basis of the difference of a single grain so if one member of a (suitably gradated) series is a heap, so is the next. Since the first member is certainly a heap, all the subsequent members are also, including the last. ${ }^{18}$

An illustration is baldness: If a man with $n$ hairs on his head is bald, then surely so is a man with just $n+1$. The same is also true of numbers: " 0 is [a] small [number]. If [some number] $n$ is small, then $n+1$ is small: Therefore every number is small." ${ }^{19}$ It is important to indicate to non-philosophers that such puzzles are not just a tease. There is no clever answer that all the professionals know; among philosophers there is no widely accepted resolution to the Sorites Paradox.

Thougl1 Sorites-vagueness is important, it would be a mistake to confine the concept of vagueness to this model of classificatory terms confronting a given continuum. A second type of vagueness attends complex predicates whose meaning is understood in terms of the application of other predicates. Philosophically, the most famous discussion of this second type of vagueness is Wittgenstein's:

Consider for example the proceedings that we call "games." I mean board-games, card-games, ball-games, Olympic games, and so

17. I don't want to give the impression that it is only nouns, adjectives, and, in general, classificatory terms that are vague. Prepositions can be vague too. See the excellent discussion of "The cat is on the mat" in John R. Searle, Expression and Meaning: Studies IN THE Theory of Speech Acts 121-22 (1979) ("If the cat was half on and half off the mat we might not know what to say ....") (I am obliged to Meir Dan-Cohen for this reference.).

18. Linda C. Burns, Vagueness: An Investigation into Natural languages and the Sorites Paradox 5 (1991).

19. Michael Dummett, Wang's Paradox, 30 SyNTHESE 301, 303 (1975). 
on. What is common to them all?-Don't' say: "There must be something common, or they would not be called 'games' "-but look and see whether there is anything common to all.-For if you look at them you will not see something that is common to all, but similarities, relationships, and a whole series of them at that. To repeat: don't think, but look!-Look, for example, at board-games, with their multifarious relationships. Now pass to card-games; here you may find many correspondences with the first group, but many common features drop out, and others appear. When we pass next to ball-games, much that is common is retained, but much is lost.Are they all "amusing"? Compare chess with [tic-tac-toe]. Or is there always winning and losing, or competition between players? Think of patience. In ball games there is winning and losing; but when a child throws his ball at the wall and catches it again, this feature has disappeared. Look at the parts played by skill and luck; and at the difference between skill in chess and skill in tennis. Think now of games like ring-around-the-rosy; here is the element of amusement, but how many other characteristic features have disappeared! ...

And the result of this examination is: we see a complicated network of similarities overlapping and criss-crossing: sometimes overall similarities, sometimes similarities of detail..$^{20}$

"Game" is a particularly rich example, but this sort of vagueness crops up whenever there is a term with a number of independent conditions of application, some but not all of which need be satisfied. "Religion" is another example. Roman Catholicism and Islam are certainly religions, and they exhibit certain features each of which seems relevant to the application of the term. These features include: (1) belief in supernatural beings or gods; (2) identification of certain objects or places as sacred; (3) rituals and ceremonies oriented towards the gods and/or towards what is sacred; (4) a moral code believed to be sanctioned by the gods; (5) feelings of awe and mystery associated with sanctity; (6) prayer and other modes of communication with the gods; (7) a world view, including perhaps a general teleology, a cosmology, and an eschatology; and so on. ${ }^{21}$ However, we would not hold that a belief-system was not a religion simply because one of the above features was not present. If a belief-system failed to associate its theology with a morality, i.e., simply because (4) did not apply, we would not, without more, say that the system was not a religion. Hinyana Buddhism, for example, is usually regarded as a religion even though there is no specific ontological commitment to a supernatural being.

20. WITTGenstein, supra note 7 , para. 66 , at 31e-32e.

21. This example is drawn from William P. Alston, Vagueness, in 8 The EnCrClopediA of PhiLosophy 219 (Paul Edwards ed., 1967). 
Multiple criteria do not necessarily lead to vagueness. "Square" applies to any figure that is (1) a rectangle and (2) has all sides equal. In this case, however, there are definite requirements for the application of the conditions: (1) and (2) are both necessary; neither alone is sufficient. ${ }^{22}$ The problem in the case of "religion" is that it is not clear which of the seven conditions, if any, is necessary, and which subset, if any, is sufficient. $^{23}$

Following Wittgenstein, philosophers use the term "family resemblance" to characterize these concepts. ${ }^{24}$ For example, one member of a family may have the Churchill nose and the jowls, another the Churchill complexion and the dimple, another the nose and the cherubic expression but without the dimple: there may be no feature they all have in common, but still they share the Churchill family face. Schenıatically, we may envisage a set of five objects each with four properties:

$\begin{array}{lllll}1 & 2 & 3 & 4 & 5 \\ \text { A } & \text { B } & \text { A } & \text { A } & \text { A } \\ \text { B } & \text { C } & \text { C } & \text { B } & \text { B } \\ \text { C } & \text { D } & \text { D } & \text { D } & \text { E } \\ \text { E } & \text { E } & \text { F } & \text { E } & \text { F }\end{array}$

There is no property or subset of the properties A-F that the objects 1 through 5 have in common. Even so, there may be a predicate $P$ that applies to 1 through 5 by virtue of their possession of some of the features A-F. Now suppose object 6 has properties A, F, G, and H. Does $P$ apply to 6 ? If users of $P$ characteristically hesitate, and if they do not call for further information about 6 , then $P$ is vague in the Wittgenstenian sense.

Sometimes the two types of vagueness combine. ${ }^{25}$ Some of the criteria for religions or for games or for being $P$ may be vague in the classification/continuum sense: at the margin it may be hard to say whether an activity is competitive or noncompetitive, whether the Virgin Mary is sup-

22. This example is also taken from Alston. See id.

23. See also supra note 4 (discussing the analytic/synthetic distinction). One might ask: How many of these criteria are supposed to be definitive of "religion" in the sense of telling us about the meaning of a word, and how many of them are supposed to be general sociological theorems about religion? And how, at the margin, can we tell the difference? Notice, however, that though the issues mentioned in this footnote are important, they are not themselves issues of vagueness. It may be possible to show that a given criterion is linked analytically rather than synthetically with "religion" without being able to specify its place in a precise array of necessary and sufficient conditions for the use of the term.

24. WrTtGensteIn, supra note 7, para. 67 , at $32 \mathrm{e}$.

25. There is also a third form of vagueness: vagueness with respect to the bounding and thus the individuation of objects. How many mountains are there in the Alps? How many clouds can one see in the sky at a given moment? Where does one cloud end and another begin? How many episodes of pain did I have today? How many offenses has a continual polluter committed? How many conurbations are there in the Bay Area: one or three (centered around Oakland, San Jose, and San Francisco)? In these cases, continuum/classification problems in boundary determination give rise to problems about identity and counting. See Alston, supra note 21, at 220. 
posed to be natural or supernatural, whether an object like 6 is $\mathrm{A}$ or is not A.

It is tempting to explain vagueness in terms of the "borderlines" of a concept's application. However, the existence of the Wittgenstenian cases means that we must be careful when characterizing vagueness in this way. The image of borderlines suggests a circle with a center, where everything is clear, and a circumference where things become uncertain. It suggests that some cases just are core cases-in law, perhaps, "easy cases"-and others just are penumbral cases-in law, "hard cases." But people may disagree about how to draw the circle. In our schematic example above, someone who takes object 5 as a core case may regard object 1 as penumbral, and she may think that object 6 is obviously $P$ if object 5 is. Someone else who takes object 2 as her core case will draw the circle differently and offer a different assessment of object 6 .

The same is true of what we regard as paradigm cases. The idea of a paradigm case is the idea of a case by reference to which one learns the use of a term. ${ }^{26}$ A child who learns to use the word "machine" in his parents' kitchen will have a different paradigm than one whose mother is a mechanic and who learns the word in her workshop. Someone who grows up in India may distinguish core and penumbral cases of "religion" quite differently from a person who grows up in an Episcopal vicarage.

These examples indicate that it may be wrong to regard vagueness as a property of words. Instead, it would appear that vagueness is a property of words' meanings. If we take "meaning" to connote the way a term is used, this suggests that vagueness is relative to users. We are all familiar with pedants who insist on great determinacy in the use of terms whose vagueness the rest of us take for granted: they refuse to say "It's freezing" unless the ground temperature is at or below $32^{\circ}$ Fahrenheit. For such a person, the term "freezing" is less vague than it is for us. ${ }^{27}$

Vagueness may be relative to other things as well: ${ }^{28}$ the purpose for which a term is being used, the time available for determining its applicability, the instruments used, and so forth. "Shorter than Clinton" may be a vague phrase if used on the basis of a quick glance at persons between 5'11' and 6' 1', and a perfectly precise phrase if there is all the time in the world to make one's measurements and no one grows in the meantime.

There is another aspect to be careful about in the borderlines model. Lawyers sometimes talk as though fact-situations could be divided into three classes in relation to a given rule: (1) easy cases where the rule obviously does apply; (2) easy cases where it obviously does not apply; and (3)

26. The paradigm case of the concept "paradigm case" is the use of a particular Latin noun such as "mensa" as a basis for learning the case-endings for the First Declension.

27. Though it may be vague for him in other dimensions: Exactly where is the ground temperature to be measured? For how long must it dip below $32^{\circ}$ Fahrenheit?

28. See SCHEFFER, supra note 10, at 49. 
hard cases or borderline cases, where it is both arguable that the rule does apply and arguable also that it does not. Similarly, logicians sometimes suggest that vague predicates might be understood in terms of a clear trichotomy of cases: a statement of the form " $x$ is $P$ " may be (1) clearly true, (2) clearly false, or (3) clearly undecidable. Both suggestions appear to instill a form of exactness into our use of vague predicates, though of course they will pose difficulties for contexts-like courts-where a bivalent rather than a trivalent logic is required. However, the trivalence idea does not do justice to the sort of vagueness that is really troubling for philosophy, science, and law.

Indeed if the division into these three categories is clear and uncontroversial, we are arguably not really dealing with vagueness at all. As Linda Burns puts it, "Where there is a clearly delimited class of cases to which the term applies, another to which it does not apply, and a third sharply delimited class of neutral instances there seems to be no real uncertainty anywhere." 29 True vagueness arises when there is hesitation or uncertainty about how to establish these three categories or where there is a general uncertainty about whether a given case is a borderline case or not. ${ }^{30}$ Undoubtedly jurisprudence made a great leap forward when it was acknowledged that the distinction between easy cases and hard cases was itself hard, so that there could be no rigid separation between the forms of judicial reasoning appropriate to the former and those appropriate to the latter. ${ }^{31}$

In general, as Israel Scheffler and others have argued, we should be wary of responding to vicissitudes like vagueness with changes in the structure of our logic. We should not be so easily persuaded to drop the bivalence of "true-or-false" and adopt the trivalence of "true-or-false-orindeterminate." Such a move does less than justice to our aspiration to rigor. We hold out to ourselves the possibility of diminishing the vagueness of our predicates as well as the reduction of other forms of verbal and semantic indeterminacy. As long as we have this aspiration, we surely need bivalent logic to embody the results of the diminution of vagueness. To paraphrase Scheffler's point: Why select certain vicissitudes-sucl as vagueness-for enshrinement in a new logic, rather than holding classical logic constant as a framework to accommodate any reduction in the hesitations or indeterminacies that afflict our use of words? ? $^{32}$

29. BURNS, supra note 18 , at 25 .

30. Burns shows that only this form of vagueness will generate the Sorites paradox. Id. at 24 .

31. See DWORKIN, supra note 12, at 265-66.

32. Schefrer, supra note 10, at 71-78; see W.V. Quine, Philosophy of Logic 85 (1970). 


\section{Can Vagueness be Eliminated?}

As a normative doctrine, "void-for-vagueness" implies that vagueness can be reduced in statutes and regulations. But can it be done away with totally? Certainly, logicians have dreamt of an ideal language for science that would eliminate vagueness altogether. In such a language, as Gottlob Frege put it,

A definition of a concept ([i.e.,] of a possible predicate) must be complete; it must unambiguously determine, as regards any object, whether or not it falls under the concept ([i.e.,] whether or not the predicate is truly assertible of it). Thus there must not be any object as regards which the definition leaves in doubt whether it falls under the concept .... We may express this metaphorically as follows: the concept must have a sharp boundary. ${ }^{33}$

The questions we face are these: How could such a language be achieved? What sort of predicates would it have to use?

It is sometimes sloppily said that what is needed is for everyone to use terms that are more specific. In fact, it is a mistake to think that vagueness varies inversely with specificity: the opposite of "specific" is "general," and there is no assurance that a reduction in generality corresponds to a reduction in vagueness. The term "tree" is more specific than the term "living thing," but it may be much easier to say whether a given object is a living thing (as opposed to inanimate) than whether it is a tree (as opposed, for example, to a bush). It may be easier to determine that something is a human community (a very general term) than to determine whether it is a city (more specific). However, the correlation does not always go this way: the specific term "chair" is less vague than "piece of furniture." Vagueness therefore seems to be independent of generality and specificity. In terms of the core/penumbra model that we were discussing earlier, vagueness has to do not with the size of the category in question, but with the determinacy of its borders.

A number of philosophers have speculated that vagueness is in principle ineliminable because it is possible to envisage puzzling borderline cases for every predicate we define. This possibility was labelled "open texture" by Friedrich Waismann. ${ }^{34}$ Others have suggested that vagueness is at least ineliminable from terms whose application involves the use of the human senses, partly because of the continuum/classification tension noted earlier. ${ }^{35}$

33. Gottlob Frege, Grundgesetze der Arithmetik, in Translations from the PhILOsophical Writings of Gottlob Frege, 159 (Peter Geach \& Max Black eds., 2d ed. 1960).

34. Friedrich Waismann, Verifiability, 19 Proc. ARistotelian Soc'y 119, 121 (1945) (supp. volume).

35. Max Black, Language and Philosophy 28-29 (1949). 
So far as open texture is concerned, it is not entirely clear to what the ineliminability claim amounts. Is it that, for any predicate $P$, there are in fact borderline cases? Or that there may, for all we know, be borderline cases? Or that we can always imagine borderline cases? The latter version seems to be the one that Waismann had in mind:

"But are there not exact definitions at least in science?" Let's see. The notion of gold seems to be defined with absolute precision, say by the spectrum of gold with its characteristic lines. Now what would you say if a substance was discovered that looked like gold, satisfied all the chemical tests for gold, whilst it emitted a new sort of radiation? "But such things do not happen." Quite so; but they might happen, and that is enough to show that we can never exclude altogether the possibility of some unforeseen situation arising in which we shall have to modify our definition. ${ }^{36}$

Waismann's case may seem fanciful as a basis for arguing for the ineliminability of vagueness in the real world. ${ }^{37}$ But I take his point to be this: if we attempt to pin down a precise meaning for a term like "gold," we do so usually on the basis of some physical theory we have of the chemistry of the elements, etc. That theory confronts a traditional field of informally distinguished items and carves it up in a determinate and scientifically useful way. We must remember, however, that such classificatory theories are neither arbitrary or a priori: they are our best response to experience. If our experience began presenting us with new objects that behaved in different ways, we should have to construct a different classificatory theory. While we were in the process of such construction, the hitherto determinate terms given by the old theory would become vague again. This has happened many times in the history of science, and we can surely expect it to recur. The situation arises particularly in the hunian sciences where theoretical determinacy is orders of magnitude less developed than in the physical and biological sciences. ${ }^{38}$

Followers of Thomas Kuhn sometimes suggest that each new scientific theory brings its own terms and its own meanings, and that between theories key terms are largely incommensurable. ${ }^{39}$ Experience, however, does not seem to bear this out. Sometimes new theoretical terms are introduced ("neutrino") and others abandoned ("phlogiston"). But often what happens is that the same words are retained with something like their old meaning,

36. Waismann, supra note 34 , at 122-23.

37. Though not as fanciful as other cases he mentions, would we apply the predicate "cat" to a catshaped animal that grew to gigantic size? Id. at 121-22.

38. See generally the excellent account of the history of taxonomy in Michel Foucaulr, ThE Order of Things: An Archaeology of the Human Sciences (1970).

39. See generally Thomas S. Kuhn, The Structure of Scientific Revolutions (2d ed. 1970). For a discussion along the lines intimated in the text accompanying this note, see RICHARD $\mathrm{J}$. Bernstein, Beyond Objectivitism and Relativism: Science, Hermeneutics, and Praxis 52-108 (1983). 
but with a new grid of organization and a new sort of tightness around the edges. ${ }^{40}$ Moreover, it seems important to the way science develops that we maintain a large stock of such terms and classifications-terms whose meaning can be subtly varied from theory to theory. Since this is so, it is unlikely that open texture, of the sort discussed in the previous paragraph, can or should be eliminated.

Is it not possible to put an end to this simply by stipulating determinate meanings for some predicates? If necessary, we could make our stipulations arbitrary, so that they were not at the mercy of possible scientific change along the lines just indicated. Is it not enough to simply designate two points on the spectrun of visible light and say, "anything at or between these points is to count henceforth as blue"? Similarly, can we not just agree to call any community of 50,000 or more inhabitants a city? Can we not stipulate that a shared belief in a supernatural deity who takes an interest in human affairs is a necessary and sufficient condition for the use of the term "religion"?

In fact, it is unlikely that arbitrary stipulation would lead to the elimination of vagueness. First, in at least some of these cases, drawing the line itself involves the use of vague terms. Consider the suggested stipulative definition of a meaning for "city." What is it to be an inhabitant? To have one's legal residence in the community in question (like George Bush's "residence" in Houston during the time of his Presidency) or to physically be there? If the latter, then for how nuch of every year? And how stable must the population level be? Suppose the population of a community in the Northeast dips below 50,000 in the winter, as the residents head for Florida. Is it still a city? ${ }^{41}$

Secondly, such stipulations would make prodigious demands on memory and measurement among users of the language that was made determinate in this way. Particularly if the stipulations were arbitrary, there would be no alternative but to learn by rote where the line was to be drawn for every predicate. ${ }^{42}$ It seems, in other words, quite unlikely that any such stipulations would succeed as linguistic conventions.

Thirdly, it is plausible to suppose that people will always have a need to communicate informally, using predicates whose application can for most cases be determined at a glance. ${ }^{43}$ Either they will invent new terms to perform this function-and thus reintroduce the inherent vagueness that goes with it-or they will subvert the newly stipulated meanings by continuing to use the terms in the old and thus potentially vague way.

40. Think of the familiar chemical elements, or the familiar names for animals, that have survived quite startling paradigm shifts in physics and biology.

41. See supra note 21 , at 220 .

42. And if they were nonarbitrary, they would be subject to exactly the changes in our sense of what was a scientifically well-founded distinction that were discussed earlier.

43. See BurNs, supra note 18 , at 178-79. 
In any case, the idea of pure stipulation is sociologically and linguistically naive. If there is a widespread feeling that the vagueness of an expression is a problem, and if the stipulation to solve that problem is supposed to be arbitrary, then there will likely be many competing stipulations. ${ }^{44}$ Most natural languages have no Academy to resolve the disputes and confusion that will result. Once people become aware of a plurality of arbitrarily stipulated delimitations of a previously vague term, they will find themselves at a loss as to which one to use. Interpersonal communication will then become vague or ambiguous all over again, for each listener will be unsure about which of the competing stipulations (if any) his interlocutor is relying on when he uses a given word.

In law as in science, meanings for terms are sometimes stipulated for specific purposes and among a specific community. However, if the terms are natural language terms and are used in a variety of contexts, then people will again be aware of a variety of stipulated meanings, and they will not be able to rule out the possibility that two or more of them may confront one another in a given instance. We can stipulate a precise meaning for "adult" for the purposes of the suffrage, and another precise meaning of "adult" for the purposes of marriage, and yet another precise meaning of "adult" for the drinking age. But these usages will be insufficient to fix a general meaning for the term-i.e., one that gives us a determinate predicate to confront a new sort of case in which adulthood seems to be at stake.

One should not exaggerate the problem. If vagueness is in general ineliminable, it does not follow that it is irreducible in a given area, or with respect to a given speech community. The most successful endeavors in this regard have involved the comparativization and the quantification of descriptions. If we insist on dividing people into those who are short and those who are tall, our terminology is going to remain vague. But we could classify people on the basis of the predicate "shorter than Clinton." Alonzo Church has argued that this sort of move is capable of eliminating vagueness altogether: ${ }^{45}$ he believes that, given sufficiently precise instruments, all individuals can be classified as either shorter than Clinton or not shorter than Clinton. The key to this proposal is, of course, "sufficiently precise instruments." As Scheffler argues, with a given set of instruments, it is always possible to imagine an undecidable case. ${ }^{46}$ We know, however, that the concept of vagueness is already relative to some purpose that informs the differentiations that someone is trying to make, and I assume Church's proposal is that, relative to any given purpose, we can always procure

44. Think of what happens among moral philosophers who insist on getting clear about the technical meanings of terms like "rights" or "deontology." There are as many competing stipulative definitions, each offered stridently in the name of analytical clarity, as there are practitioners of this dubious art.

45. Alonzo Church, Relative, in The Dictionary of PhLosophy 269 (Dagobert D. Runes ed., 1942).

46. SCHEFFLeR, supra note 10 , at 60 . 
instruments that enable us to eliminate vagueness in the use of comparative terms like "shorter than." Indeed, this is precisely the basis of measurement in the modern world. "Less than one meter tall" is just another way of saying "shorter than the standard meter rod preserved in Paris."

The other way of reducing or eliminating vagueness from a certain sphere of application is to renounce the use of classificatory predicates altogether. Scientific laws, for example, are increasingly not formulated in terms like "everything which is $P$ is $Q$ " or "an event of type $P$ will always be followed by an event of type $Q$." Instead, predicates are used simply to designate continua, or dimensions of continuous variation, and laws are stated that make variations in one continuum a function of variations in anotlier: "change in $p=f$ (change in $q$ )."

Occasionally, thougl more crudely, we do the same sort of thing in law. We do not just say, "The rich should pay a greater proportion of their income in tax than the poor." Instead we define a complex function $f$ and legislate: "tax payable $=f$ (taxable income)." The example illustrates, how" ever, two residual sources of indeterminacy. First, it is still necessary to define the relevant continua: we all know how difficult that is with regard to "taxable income." Second, in working with these continua, there are fine discriminations that we simply stipulate away, ignoring pennies or rounding up to the nearest dollar.

\section{CONTESTABILITY}

I now want to move to the third kind of indeterminacy that I defined: contestability. A phrase becomes contestable when it is clear that it embodies a normative standard, but different users disagree about the detailed contents of that normative standard.

Let me begin with a couple of examples. The Eighth Amendment to the United States Constitution says the following:

Excessive bail shall not be required, nor excessive fines imposed, nor cruel and unusual punishments inflicted. ${ }^{47}$

What counts as excessive bail or an excessive fine? Presumably a sum that is larger than it ought to be. But what ought to be the level of fines and bail bonds? This is something that people disagree about, and those disagreements will shape their quarrels about the meaning of "excessive." What makes a form of punishment cruel? It is, presumably, the point of punishment to be unpleasant; so a cruel punishment would seem to be one that is more unpleasant than it ought to be. But again people disagree about how unpleasant punishment ought to be.

Similar issues arise with regard to the Fourth Amendment:

47. U.S. CoNST. amend. XIII. 
The right of the people to be secure in their persons, houses, papers, and effects, against unreasonable searches and seizures, shall not be violated . . . . ${ }^{48}$

What counts as an unreasonable search or seizure? It is difficult to say much more, on the basis of the meaning of the words themselves, than this: an unreasonable search or seizure is one for which there is insufficient justification either as to the occasion or as to the manner in which it is conducted. Once again, disagreement in the community about when and how it is appropriate for the police to search for evidence of wrongdoing will surface in disputes about the meaning of "unreasonable."

In other words, it looks as though these constitutional provisions invite us to make value judgments about appropriate levels for financial penalties and other punishments, and about appropriate levels of justification for police actions. The problem is that we disagree about such value judgments. The mere fact that terms like "unreasonable" or "excessive" invite us to make value judgments does not in itself undermine the determinacy of their meanings. On the contrary, it is part of the meaning of these words to indicate that a value judgment is required, a function which the words perform quite precisely. To drainatize the point, we might rephrase the amendments in question as follows:

The right of the people to be secure in their persons, houses, papers, and effects, against searches and seizures which are [make valuejudgment here], shall not be violated ... . Bail which is [make value-judgment here] shall not be required, nor shall fines which are [make value-judgment here] be imposed, nor shall punishments which are [make value-judgmeut here] and unusual be inflicted.

So the terms do have a clear meaning: the rule for their use is to elicit a value judgment from anyone applying or implementing the proposition in which they appear. The fact that they do not in addition tell us which value judgments to make does not detract from their univocality. It does make it likely, however, that in a society torn by value conflicts, different people will apply the provisions in different ways.

In fact, words like "unreasonable" and "excessive" give us a little more help than is indicated in the account just given. Some normative terms pin things down more specifically than others do, and different normative terms will do so in different ways. "Bad," "unreasonable," "wicked," "excessive," "undeserving," "wrong," "malicious," and "a violation of rights" are all fraught with negative connotations of value, but they carry those connotations in different ways. "Excessive," for example, indicates that we are to make a value judgment about amount or quantity; it does not invite us to make a value judgment about the beauty of the judicial rhetoric that accompanies the imposition of a fine. "Unreasonable" looks to the justifications

48. U.S. CoNsT. amend. IV. 
there might be for an action; it does not invite us to consider whether the action is, for example, shocking or unprecedented, except as relevant to the issue of justification. In these ways, each of the terms we are considering pushes us in the direction of a particular dimension of evaluative significance and away from other dimensions.

One way of putting this is that each of the various terms has a quite specific evaluative meaning, even though people disagree about the criteria for the term's application. ${ }^{49}$ Two judges may agree that the phrase "excessive bail" requires them to make a value-judgment about the amount of bail required, but they may disagree about the cut-off point at which the amount of bail for any particular charge becomes excessive. In addition, the specific evaluative meaning may be disputed, or change over time. An instruction to sentence people in accordance with their "desert" gives the judge a different and more specific evaluative task than one which empowers her to impose whatever sentence is appropriate. Two judges may recognize that difference even though they disagree about whether desert is purely a function of past conduct or should encompass a defendant's future prospects for rehabilitation.

So far I have concentrated on strict evaluative meaning. In addition, an evaluative term may have an element of relatively fixed descriptive meaning. A prohibition on cruel punishment, for example, is not an allpurpose invitation to make a value-judgment about punishment. A light sentence may not be struck down under the Eighth Amendment because it violates a victim's rights; nor does the provision allow the state to appeal against the costs of administering a particular penalty imposed by a court. In ordinary language, the descriptive meaning of "cruel" invites us to focus our evaluation specifically on the degree or quality of the suffering experienced by the prisoner and perhaps on the disposition and attitude of those inflicting it.

Beyond that, "cruel" remains indeterminate. We know that it has negative and condemnatory connotations, and we know that it tells us something about the gravity of the suffering experienced. However, people will differ as to whether cruelty is simply a matter of the intensity of the suffering, or whether it also refers to the malice, inhumanity, or disrespect with which the suffering was inflicted.

Either of these positions, considered in itself, might be a plausible account of the descriptive meaning of the term. But when "cruel" is also used as an evaluative term, particularly in a constitutional context, the possibility of these alternative accounts introduces something called "political contestability" into the word's meaning. For now, we are not merely saying (as a semantic matter) that "cruelty means the malicious infliction of pain" or "cruelty means the experience of extreme suffering." By ascribing one

49. For discussions of meaning and criteria, see R.M. Hare, The Language of Morals 94-110 (1952). 
or other of these meanings to a term that is used in a legal or constitutional context, we are saying, in effect, "do not allow pain to be inflicted maliciously" or "do not allow the infliction of extreme pain." Since we may disagree substantively about the merits of these latter principles-particularly in a penal context-the word "cruel" is bound to become an arena for our wider moral and political disagreements.

\section{VII \\ Essential Contestability}

About thirty-five years ago, W.B. Gallie introduced the idea of "essentially" contested concepts. ${ }^{50}$ This idea, which has been quite influential in political theory, bears some discussion in the present context. What does "essential" add to contestability as defined above? It is not just an intensifier. To call a concept essentially contested is not merely to say that its meaning is very, very controversial. Nor is it to say merely that the disagreements which surround its meaning are intractable and irresolvable. ${ }^{51}$ Interpreted strictly, "essentially" might indicate any one or more of three notions.

First, it indicates that the dispute about the meaning of the concept in question is a dispute that goes to the heart of the matter. It is not merely a dispute about marginal or penumbral cases between persons who are clear about the concept's core. It is a dispute that can generate rival paradigms because it is a dispute between differing accounts of the essence or central meaning of the concept. Thus "deinocracy" is essentially contested because people do not just disagree about evidently marginal cases like Kuwait, but also about whether a direct, participatory system like ancient Athens should be taken as a paradigm, relegating the representative system of the modern Uinited States, say, to a penumbral position, or whether the paradigm should be a modern representative system like the United States or like the Westminster system, with Athens dismissed as an historical peculiarity.

Second, the idea of "essential" contestability can be taken to indicate that contestedness is part of the very meaning of the expression in question: it is part of the essence of the concept to be contested. Someone who does not realize that fact has not understood the way the word is used. This does not prevent a person from putting forward a firm view about the concept or taking sides in the controversy about its meaning. But anyone who says that "freedoin," for exaniple, has a perfectly clear nieaning and that he cannot see why so nrany people get it wrong, shows that he himself does not understand the most striking rule for the use of "freedom" in the modern

50. W.B. Gallie, Essentially Contested Concepts, 56 Proc. ARISTOTELIAN Soc'y 167 (n.s. 195556).

51. Cf. Steven Lukes, Power: A Radical View 9, 26 (1974) (evaluating power as an "essentially contested concept"). 
world - namely, that it is a verbal arena in which we fight out our disagreements about the nature of human agency and autonomy.

It is true that we often think of meanings as things that are necessarily agreed: the meaning of a term is simply a consensus among its users to deploy it in a certain way. However, in his article, Gallie explored the possibility that, for certain terms, meaning inay be tied (conventionally) to the existence of a controversy (or a range of controversies) rather than to the existence of a consensus. There may, as he said, be "concepts the proper use of which inevitably involves endless disputes about their proper uses on the part of their users."52

Together, those two elements define the basic meaning of essential contestability for Gallie. 53 Additionally, "essential" can indicate a third idea: that the disagreement is in some sense indispensable to the usefulness of the term, that it serves some purpose associated with the contested expression. This was the main thesis of Gallie's article: he argued that we should not assume that something has gone wrong necessarily when people disagree about the meanings of words. A controversy from aesthetics may serve as an illustration.

Art critics soinetimes argue about whether advertisements, rock music, photographs, and Ninja Turtle cartoons should be regarded as forms of art. In the course of these debates they must ask themselves questions, not only about the objects at issue (their nature, complexity, qualities, authorship, audience, cultural prominence, and circumstances of production, for example), but also about what art is, what makes something a work of art, as opposed, say, to a mere commercial artifact. What they find is that they

52. Gallie, supra note 48 , at 169 .

53. Gallie specifies five basic criteria for a concept to be considered "essentially contested":

(I) Value-Concept: The concept must be an evaluative or appraisive concept- "in the sense that it signifies or accredits some kind of valued achievement." Id. at 171.

(II) Complexity: "This achievement must be of an internally complex character, for all that its worth is attributed to it as a whole." Id. at 171-72. To judge something as art or democracy, for example, is to make a complex judgment about it that will involve many aspects. It is different from judging something to be "red."

(III) Variously describable:

Any explanation of its worth must therefore include reference to the respective contributions of its various parts or features; yet ... there is nothing absurd or contradictory in any of a number of possible rival descriptions of its total worth, one such description setting its component parts or features in one order of importance, a second setting them in a second order, and so on.

Id. at 172.

(IV) Openness: "The accredited achievement must be of a kind that admits of considerable modification in the light of changing cireumstances; and such modification cannot be prescribed or predicted in advance." Id.

(V) Aggressive argumentation:

[N]ot only [do] different persons or parties adhere to different views of the correct use of some concept but ... each party recognizes the fact that its own use of it is contested by those of other parties, and ... each party must have at least some appreciation of the different Id. criteria in the light of which the other parties claim to be applying the conecpt in question. 
cannot agree about the definition of "art." For some, art is essentially a formal and intellectual achievement, an essay in the configuration of relatively detached elements or ideas undertaken for its own sake. For others, the essence of art is its contribution, direct or indirect, to the representation of reality and possibility, and so to the practical powers of the human imagination. For still others, art is essentially expressive either of the striving or virtuosity of some individual creator, or of the moving spirit of some community in which the artist participates. Thus the debate about the classic Coca Cola bottle, or Jagger and Richards' "Satisfaction," or Donald Duck quickly becomes at least in part a debate about the meaning of the concept of art. $^{54}$

Although rival conceptions ${ }^{55}$ of art are put forward in these debates passionately and fervently, as though the issue mattered, as though it were not simply a verbal disagreement, there seems to be little prospect of resolving such definitional disputes. Everyone argues as though her own conception were the right one, but everyone knows there is no authoritative dictionary that could settle the true meaning in a way that all the contestants would acknowledge. It is a debate in which it is impossible to imagine anyone having the last word.

Even so, any suggestion that the dispute is futile and that the contestants should disengage by simply abandoning the contested term and coining new words (art, schmart; $\operatorname{art}_{1}$, art ${ }_{2}$; and so on) to embody their respective definitions is likely to be met with derision. The contest continues to be seen as important and unavoidable, even while it is acknowledged to be irresolvable. Indeed, not only does the contest continue but as Gallie points out, "each party continues to defend its case with what it claims to be convincing arguments, evidence and other forms of justification," each party knows very well that what it claims to be convincing does not in fact convince.

According to Gallie, this shows that certain terms are important and valuable not despite their contestedness but because of it. Far from contributing to semantic confusion, the disagreements occasioned in the use of art play a worthwhile role in social, intellectual, and cultural life. ${ }^{57}$ No doubt there are cases in which a debate between rival definitions of a term would simply muddy the dialectical waters, confusing discussion and facilitating talk at cross purposes to no good effect. Often, however, the defimitional dispute enriches the wider debate in which the disputed concept is

54. "In part" because even if a definition of "art" were agreed, there would still be enormous debate about whether such objects in fact satisfied criteria as abstract as those which the agreed definition would inevitably embody.

55. Different uses of a contested concept are sometimes called "conceptions." For the distinction between concept and conception, see Ronald Dworkin, Taking Rights Seriously 134-36 (1977). See also DworkIN, supra note 12, at 70-72.

56. Gallie, supra note 48 , at 168.

57. See id. at 180-83. 
deployed, and in many cases the contestants themselves are able to grasp the benefit of the polemic, even while they remain unregenerate partisans of their own respective points of view. Would anyone deny, for instance, that an understanding of art is enhanced, rather than impoverished, by the continuing debate among artists, art critics, and aesthetes about what art "really" is? The dynamics of that debate-putting forward views, citing and assembling examples, responding to rival views with arguments and counter-examples, modifying one's view to meet exceptions, explaining why it is still coherent even after modification, developing schools of thought which evolve partly in response to internal dynamics and partly in response to rival pressures, locating each view in a history and heritage of disputation, opening one's aesthetics in various ways to contributions from other spheres of life and thought, relating one's aesthetics to rival conceptions of the good life for those endowed with talent, and so on-results in any modern claim about the nature of art being considerably richer and more subtle than it would have been if the claim had issued straightforwardly from an historically unchallenged consensus.

Many political concepts are also important for their contestedness. Our earlier example of democracy is a good illustration. What is the true meaning of "democracy"? Can the judicial review of representative or plebiscitary legislation be described as democratic if it is done in the name of individual rights? Is the concept of "one-party democracy" a contradiction in terms or can there be democracy without divisive political factions in a society? Are representative institutions really democratic, or are they, as the Athemians believed, either oligarchic because they concentrate power in the hands of the few or aristocratic because voters take themselves to be choosing the "best" candidate? Can there be democracy under conditions of economic inequality? Does political denıcracy require social democracy? And so on. It is idle to pretend that there are definitive answers to these questions - answers given in the Gettysburg address or in Webster's Dictionary. But the debate continues vigorously and fruitfully, despite the absence of guaranteed answers.

For these reasons, these are not debates we should seek to bring to an end by stipulating more precise or less contestable meanings for our terms. Few of the parties to the American debate about democracy and constitutional adjudication would settle for a resolution that defined two distinct meanings for the word "deniocracy" 58 and separated the antagonists on the ground that they were talking at cross purposes. Their debate is about what democracy really is, and it is arguable that understandings on all sides of this vexed area of political theory are enriched rather than confused by the persistent disagreement.

58. Democracy could be defined as 'democracy, which allows judicial review, and 'democracy' which does not. 
In Gallie's original exposition, the usefulness of conceptual disagreement was understood in terms of the development of some original exemplar or paradigm. A concept is essentially contested (as opposed to "radically confused"), he said, when the rival conceptions refer back to some original exemplar of the concept "whose authority is acknowledged by all the contestant users" and whose achievement is sufficiently complex to be describable in various ways. ${ }^{59}$ For example, disagreements about the meaning of "the Christian way of life" are held together by reference to the Gospel accounts of the life of Jesus of Nazareth; each conception purports to provide the best account of what that complex exemplar stands for. The usefulness of the contestability is then expressed in terms of the plausibility of supposing that the heritage of the exemplar's original achievement will be promoted rather than undermined by ongoing disagreement about the meaning of the concept. ${ }^{60}$

But reference back to an exemplar may be too narrow an account of what makes a contested concept nevertheless a shared concept. In legal contexts, it may be that the authoritative specification of a term is what matters. ${ }^{61}$ Given the source, we may have no choice but to conduct our battles of principle about punishment, for example, on the ground defined by the phrase "cruel and unusual." In other contexts, it may be that there is just a history of disputation in which a given term has played a major role, so that continuing in that quarrelsome tradition means, again, fighting on that particular verbal ground. This is certainly a more accurate account of the contestedness of "democracy" than any reference back, for example, to Athens as an exemplar. For these disputes, an exemplar and (or) a paradigm may emerge in the course of discussion as, in Ronald Dworkin's words, "a kind of plateau on which further thought and argument are built," 62 rather than as a foundation that makes the argument possible in the first place. Their emergence and the fact that they "help to sharpen argument and ... improve the community's understanding of its intellectual environment" are signs that a conceptual contestation is fruitful, rather than explanations of its fruitfulness. ${ }^{63}$

Someone might object that this idea of an essentially contested concept is incoherent, for it moves equivocally between a participant's and an observer's point of view. To a participant, nothing seems to matter more than that his definition be sustained and his opponent's refuted. He is not saying simply, "Here's one more view about democracy to put in the catalogue." Surely each proponent is saying, "This is what democracy really is.

59. Gallie, supra note 48 , at 180 .

60. Id. at $180-81$.

61. One example would be the use of an expression by the framers in the original text of the Constitution.

62. Dworkin, supra note 12 , at 70.

63. Id. at 71. See generally id. at 68-76, 90-101, 424-25, for Dworkin's excellent discussion of these matters. 
This, and not those other views, captures the true essence of the concept." An observer, however, will say: "J.W. thinks he's going to win, but he must know in the back of his mind that the discussion is unwinnable. So why is he making so much fuss? There are no right answers here: democracy is an essentially contested concept." Can these perspectives be combined? Is it possible to engage in one of these debates as a partisan of a particular view but also as a theorist who knows why disputes of this kind are valuable as well as intractable? Can one acknowledge that a concept is essentially contested and still claim that one's own view is right and one's opponent's view wrong?

The answer is a cautious "yes." One cannot expect to prevail comprehensively - that is, to have one's opponents say, "But of course! J.W.'s definition of 'democracy' is correct. Why didn't we all see that before?" One understands the ideological and philosophical sources of persistent controversy. Realistically to hope to prevail in such a dispute is to believe, first, that one can convince others to take more seriously the considerations one has been advancing; second, that one can explain why alternative views are less persuasive than they have been thought to be; and third, that though one expects a continuation of the debate in both familiar and novel forms, one thinks one will have something to say about any alternative view or argument that might imaginably come up. Someone who has these hopes will acknowledge that he is engaged in a debate whose richness and usefulness stems only partly from his own contribution; but he will aim to show that this rich and useful fabric of argumentation culminates in the desirability of according greater recognition to his view.

\section{. VIII \\ Are Vagueness and Contestability Undesirable in Law?}

It is often assumed that vagueness and contestibility are undesirable in the law - and this is certainly the impression given by the "void-for-vagueness" doctrine. To the extent that the meaning of a term used in a statute, a regulation, or a constitutional amendnient is indeterminate, the person to whom it is addressed may not know exactly what is required of her. To that extent, she does not know how to discharge her duty of fidelity to the law. ${ }^{64}$ In addition, if she expects the provision to be enforced, she may be left unsure as to how, exactly, the enforcement powers of the state will be used against her. She therefore does not have a clearly defined realm of personal or economic freedom that she can count on. ${ }^{65}$

64. This consideration is almost always overlooked in discussions of the subject. Proponents of "The Rule of Law" assume that predictability of the use of power, see infra note 63, is the only thing at stake. Some of us, however, take fidelity to law seriously as an issue in its own right, quite apart from worries about enforcement.

65. See F.A. HAyek, The Constitution of Liberty 152-53 (1960). 
However, these concerns are easily exaggerated. Nothing that has been said so far shows that if a term is vague, it is comprehensively vague, or that if a term is contested, all instances of its use are contested. Though color predicates are vague, we pass information about colors to each other all the time. Though a term like "cruel" is contested, no one doubts that burning people alive in an auto-da-fé would be a cruel mode of execution. Faced with a provision that says "no act of type $P$ shall be performed," we may be perfectly clear about its application to a given act $\left(x_{1}\right)$ even though $P$ is in other cases indeterminate: we will say to ourselves "Of course $x_{1}$ would be $P$." The considerations adduced in the previous Parts do show that we are often not in a position to articulate a comprehensive or uncontroversial meaning-rule from which this statement would follow along with all other applications of $P$. However, we do not need such a rule to see that $x_{1}$ would be $P$. Indeed, as Wittgenstein has stressed, it may be only because we understand that $x_{1}$ is certainly $P$, and $x_{2}$ is certainly $P$, and so is $x_{3}$, that we regard $P$ as vague. It is because we cannot formulate a rule specifying what $x_{1}-x_{3}$ have in common that we have difficulty applying $P$ to a problem case such as $x_{4}$. Think how much easier it would be to pin down a defimition for "game" if the term did not include ring-around-the-rosy, solitaire, and baseball. Thus, vagueness anywhere presupposes determinacy somewhere else; only the determinacy it presupposes cannot in the nature of things be articulated as rule-governed determinacy.

For many cases, then, the vagueness of the terms used in a legal provision may be of little concern to the citizen or the official. Furthermore, one who is instructed to avoid actions of type $P$ may be disposed to avoid actions that are even arguably of type $P$. For example, the vagueness and contestedness of "homicide" are issues for most of us only in extraordinary circumstances. Only if we have an independent reason to be pushing up as close as possible against the limits of the provision will we be concerned about its vagueness. A doctor serving terminally ill patients may be in this situation with "homicide"; so may an official whose job it is to draft heavier and heavier penalties in the war on crime, in relation to the contestedness of "cruel." But most people are not placed in such a situation with regard to numerous legal provisions. The citizen needs to know what the law requires of him, but that is not necessarily the same as needing to know exactly how far he can go before his behavior becomes an infraction. "How close can I get to coercing a woman before it counts as rape?" "How active does my assistance in a person's death have to be before it counts as murder?" "How much may I mislead a business partner before it counts as fraud?" A legal profession which poses these and similar questions as crucial for the ordinary citizen's understanding of the law is already in ethical difficulty. ${ }^{66}$

66. The same may be said of slippery-slope and bright-line arguments against the redefinition of various offenses such as sexual harassment. Someone for whom the important question is "How much 
There are, of course, provisions for which such inquiries are reasonable. "How fast may I drive before I am guilty of excessive speed?" "What is the minimum number of years I need to have been in the country before I can become a citizen?" "How much must I pay in sales tax?" But it is striking that for these cases we specify reasonably precise measures: "Fifty-five miles per hour," "Five years," and "Eight percent of the purchase price." This suggests that in some of the cases where we do not specify numerical limits, cases where we employ instead a relatively vague concept, it may be because we do not think it appropriate for citizens to be finely calibrating their action in very close proximity to legal boundaries. These may be cases where we think it a mistake for us, as a community, to get into the business of specifying rules too precisely.

In defense of the view that I have been criticizing, it has been said that vague provisions are unfair. If a citizen sails close to the limits, he is likely sometimes to be found guilty of an offense by a court which stipulates a different arbitrary boundary from the one he chooses to observe. When this happens, the complaint goes, the citizen is a victim of retroactive legislation. No doubt there is some justice to this complaint.

We need to remember, though, how different this is from the case in which the citizen is suddenly faced with a new statute criminalizing past behavior that was perfectly and uncontroversially lawful when it was performed. The latter is tbe case to which our intuitions about the injustice of retroactivity are formed. By contrast, in the case of the vague provision, the citizen is not completely blindsided. The fact that there is a law and the fact that it uses a predicate the vagueness of whose meaning is well understood by everyone provide some sort of notice. The citizen knows that he is in a delicate situation and is taking a risk. He may have a particular complaint in regard to a particular provision: maybe a more determinate expression was available and ought to have been used, so as to give him clearer notice. But since determinacy is not always available, since legislation is nevertheless necessary, and since it is of course only arguable cases that are going to come before a court, it would be simplistic to say as a matter of course that courts are guilty of the evil of retroactivity whenever they make a decision one way or the other about vague provisions that come before them.

On the other hand, the case for vagueness is also sometimes exaggerated. It is said that we should value the open texture of the language used in legislation: since a human legislator cannot possibly contemplate all the cases relevant to his concerns, the vagueness of the expressions gives courts a chance to be flexible in regard to new and unanticipated applications. H.L.A. Hart puts the argument this way:

may I flirt with my student before it counts as harassment?" is already poorly positioned with regard to the concerns underlying harassment law. 
It is a feature of the human predicament, not only of the legislator but of anyone who attempts to regulate some sphere of conduct by means of general rules, that he labours under one supreme handicap-the impossibility of foreseeing all possible combinations of circumstances that the future may bring. . . . This means that all legal rules and concepts are "open"; and when an unenvisaged case arises we must make a fresh choice, and in doing so elaborate our legal concepts, adapting them to socially desirable ends. ${ }^{67}$

In fact, however, many unanticipated cases where flexibility is desirable have nothing to do with vagueness. Consider the old problem of "No vehicles in the park." Someone has a heart attack in the park and an ambulance is called in: has the prohibition been violated? Clearly the case is one where we should want flexibility, but it has nothing to do with vagueness. An ambulance is not a borderline case of a vehicle; if anything it is a paradigm case of vehicle. We call for an ambulance precisely because we need a vehicle to transport the sick person. There are some imaginable instances where the need for flexibility and the existence of borderline cases go together. Lon Fuller's example of the veterans who want to place a Second World War jeep on a plinth as a monument in the park is an example of this, inasmuch as we may hesitate about whether to call the immobilized shell of a jeep a vehicle. ${ }^{68}$ But we must not make the mistake of assuming that the vagueness of natural language predicates matches our pragmatic uncertainty about what should be done in future or unanticipated cases. Vagueness may be an indication of classificatory uncertainty, but that is not always the same as political or moral uncertainty about what ought to be done in a given case. ${ }^{69}$

Let us return to the original objection about the use of vague terms in the law. Perhaps the complaint is not about "retroactive" decisions as such, for of course, courts have to reach some sort of decision in the cases that come before them, but about decisions that go against the interests or liberty of the citizen. It is sometimes suggested that, in criminal statutes at any rate, all doubts about indeterminate meanings ought to be resolved in favor of freedom: the presumption should be that conduct is not an offense unless it is clearly prohibited. However, the utility of this suggestion is limited in two ways. First, it applies at most to criminal law. In civil law actions, it is

67. H.L.A. HART, Jhering's Heaven of Concepts and Modern Analytical Jurisprudence, in Essays in Jurisprudence AND PhILosophy 265, 269-70 (1983). See also my Critical Notice of that collection, in 94 Mind 281 (1985).

68. Lon L. Fuller, Positivism and Fidelity to Law-A Reply to Professor Hart, 71 Harv. L. Rev. 630,663 (1958).

69. Some loose uses of the term "pragmatic" are often appealed to in order to blur this distinction. Our classificatory uncertainty is, in a sense, pragmatic; so is our political uncertainty. But our purposes do not all run together. The point of classifying things, generally, with a range of natural language predicates, is seldom the same as the point of classifying things in law as "to be done" and "not to be done." 
by no means clear that a defendant should always be the one to get the benefit of any indeterminacies in the relevant provision, any more than it is clear that agencies should receive the benefit of such a presumption in administrative law. ${ }^{70}$ Secondly, it applies best in regard to those expressions for which there is a reasonably bright line between clear applications and borderline applications. But as we saw in Part V, that boundary is often not clear. To the extent that the boundary is disputed, is a defendant to receive the benefit of that doubt also? And then what about the borderlines of this second level of indeterminacy?

Is it never unfair, then, to impose vague rather than precise requirements on a person? One example in which it is not fair is the case of a legal provision which actually requires a person to meet a positive standard: for example, an official nuay be required to ensure a "speedy" trial for a defendant. In that case, the vagueness of the concept may leave the official unsure about his exact duty. It will not be enough for him to steer well clear of the more flagrant types of delay. The same is true of a requirement that a person stopped by the police must produce "credible and reliable" identification: ${ }^{71}$ a good-hearted citizen may steer well clear of obviously spurious forms of identification (library card, New Zealand driver's license, selfaddressed envelopes, and so forth), but still be unable to work out what he is actually required to carry with hin.

Another case in which vague requirements are unfair involves forms of vagueness and contestedness that do not exhibit anything like a core/ penumbra structure. A piece of strict sabbatarian legislation that forbids "the playing of games" on a Sunday nray be burdensone if we have no idea what are regarded as paradigm cases and what are considered as borderline cases. Is the purpose of the legislature to prevent noise on Sundays, or exertion, or entertainment, or frivolity, or gambling, or competitiveness, or outdoor pursuits, or pleasure? In this case, the vagueness of the term, without more, leaves even the pious citizen with no idea how to orient herself in regard to the provision.

Even in this last example, however, there may be some point to the use of the vague expression "game," rather than sone more determinate phrase such as "team sports played competitively outdoors." Suppose there existed a traditional biblical text that proscribed "the playing of games" on the Lord's Day, much as the Fourth Commandment proscribes "laboring." No doubt, various biblical scholars would argue back and forth on the true meaning of the expression and give reasons for one interpretation rather than another. A Judaic or Christian fundamentalist might think it worthwhile to insert that biblical proscription directly into our law without further

70. See also the excellent discussion of "Conventionalism" in DwORxIN, supra note 12, at 114-50, especially the section on "Faimess and Surprise," at 140-44.

71. See Kolender v. Lawson, 461 U.S. 352, 353 (1983) (holding such a requirement unconstitutionally vague). 
clarification, for his aim may be, not to regulate conduct, but rather to turn a theological debate into a legal debate. Even though he has not pinned down a precise meaning for "game," his purpose may still be to make our society a more devout society. For him, that might mean less the prohibition of any putative "game" in particular, and more the institution of a public political practice of arguing about the proper meaning of the prohibition. He may think a society may or may not be devout if it permits children to jump rope on a Sunday, but a society is certainly not devout if the status of jump rope on a Sunday is not even an issue for that society. The religious exanple is an implausible one, for us at any rate. Still, an analysis like this may be important for our understanding of the dialectical role that contested terms can play in constitutional jurisprudence.

Consider again the Eighth Amendment: "cruel and unusual punishments" shall not be inflicted. The meaning of "cruel," we know, is contestable, and for some jurists that is a flaw: if only the framers had specified whether capital punishment was permissible or not, then we would know where we stand. But knowing where we stand may not be the point of the provision. Instead, the point may be to ensure that certain debates take place in our society: this should not be a society which simply imposes punishments without regard to whether or not they are cruel. Maybe execution is cruel, maybe it is not. But a society which executes criminals without hesitation and without public debate on that question is arguably a poorer society, from the point of view of the ethical theory underlying the Eighth Amendment, than a society which makes it an issue.

Another example: it may be contestable whether flag-burning is to count as "speech" or not for the purposes of the First Amendment. In the middle of a tedious constitutional law class, we may wish that the framers had used a more precise expression than "speech." But that, too, may be a mistake. The point of restraining Congress from abridging freedom of speech may have been to make it an issue - a big deal, a Federal case (in the vernacular sense of that term)-when spoken dissent, or anything arguably like it, is restrained. In other words, the point of the First Amendment might be as much to facilitate a debate about "speech" as to secure a bottom-line of legislative restraint.

Perhaps, then, we sometimes try too hard to determine a precise prescriptive meaning for legal and constitutional provisions. Our urge is to get into a position where we can always answer the question, "Well, is this prohibited or is it not?" However, sometimes the point of a legal provision may be to start a discussion rather than settle it, and this may be particularly true of the constitutional provisions that aim at restricting and governing legislation. ${ }^{72}$ The purpose of these provisions may be to have an impact on

72. In some countries, this is the explicit function of constitutional provisions. The New Zealand Bill of Rights Act of 1990, for example, specifically precludes the courts from striking down Acts of Parliament ( $\$ 4)$, but $\$ 7$ requires the Attorney General to "bring to the attention of the House of 
the process of legislating rather than merely on the validity of legislation conceived as some sort of finished product. The rule of law, under this account, involves not just the production of determinate norms, but respect for a certain heritage in the subject matter and style of our legal and political debates.

If this is true, then the use of contestable terms should not necessarily be regarded as a flaw in a legal provision. Particularly if the term in question is "essentially" contested in Gallie's sense-i.e., if continuing debates about its proper meaning are understood to serve some important function associated with the employment of the term-then its use (rather than the use of a more determinate surrogate) may be crucial for the style of politics that we want to foster in our community. It follows, also, that the Critical Legal Studies exposé of the "contradictions" and "indeterminacy" inherent in our legal language is neither surprising nor damning. ${ }^{73}$ Of course, some words and concepts that we use in our law will reflect a heritage of fundamental disagreement and facilitate the protraction of such controversies. But far from undermining the legitimacy of the law, that is the whole point of their deployment. We do not agree on many things in our society, but perhaps we can agree on this: that we are a better society for continuing to argue about certain issues than we would be if such arguments were artificially or stipulatively concluded.

Representatives any provision in the [piece of proposed legislation] that appears to be inconsistent with any of the rights and freedoms contained in this Bill of Rights." New Zealand Bill of Rights Act § 7(b), 109 N.Z. Stat. 1687, 1689 (1990).

73. For a more general argument to this effect, see Ken Kress, Legal Indeterminacy, 77 CALIF. L. REv. 283 (1989). 